\title{
PROJETO POLÍTICO-PEDAGÓGICO: IDEOLOGIA E UTOPIA ${ }^{1}$
}

\author{
PROYECTO POLÍTICO PEDAGÓGICO: IDEOLOGÍA Y UTOPÍA
}

PEDAGOGICAL POLITICAL PROJECT: IDEOLOGY AND UTOPIA

\author{
Maria Zélia Borba ROCHA ${ }^{2}$ \\ Shayane Cristina MORAES ${ }^{3}$
}

RESUMO: O projeto político-pedagógico é um documento de gestão escolar, obrigatório para as escolas públicas, estabelecido na legislação federal brasileira. O objetivo da pesquisa realizada foi desvelar a ideologia e a utopia subjacentes aos projetos político-pedagógicos. A pesquisa empírica de metodologia mista foi realizada em dois períodos: 2010-2012 e 20182019, e empregou, como método quantitativo, o método indutivo, e na base qualitativa, a Hermenêutica de Profundidade. O método indutivo forneceu os critérios de coorte na coleta dos dados e a Hermenêutica de Profundidade propiciou o desvelamento da ideologia e da utopia ocultos nos conteúdos dos projetos político-pedagógicos. A análise qualitativa, por intermédio da Hermenêutica de Profundidade, recorreu aos conceitos de ideologia e de utopia na perspectiva mannheimiana. A análise conseguiu identificar quatro componentes ideológicos e um componente utópico.

PALAVRAS-CHAVE: Gestão escolar. Gestão democrática. Planejamento estratégico. Hermenêutica de profundidade. Teoria mannheimiana.

RESUMEN: El proyecto político-pedagógico es un documento de gestión escolar, obligatorio para las escuelas públicas, establecido en la legislación federal brasileña. El objetivo de la investigación realizada fue desvelar la ideología y la utopía subyacentes a los proyectos político-pedagógicos. La investigación empírica de metodología mixta fue realizada en dos periodos: 2010-2012 y 2018-2019, y empleó, como método cuantitativo, el método inductivo, y en la base cualitativa, la Hermenéutica de Profundidad. El método inductivo proporcionó los criterios de cohorte en la recolección de los datos y la Hermenéutica de Profundidad propició el desvelado de la ideología y de la utopía ocultos en los contenidos de los proyectos político-pedagógicos. El análisis cualitativo, por intermedio de la Hermenéutica de Profundidad, recurrió a los conceptos de ideología y de utopía en la perspectiva mannheimiana. El análisis logró identificar cuatro componentes ideológicos y un componente utópico.

PALABRAS CLAVE: Gestión escolar. Gestión democrática. Planificación estratégica. Hermenéutica profunda. Teoría mannheimiana.

\footnotetext{
${ }^{1}$ A primeira versão deste trabalho foi apresentada no VI Congresso Iberoamericano de Política e Administração da Educação, realizado simultaneamente com o IX Congresso Luso-Brasileiro de Política e Administração da Educação, na Universidade de Lleida, Espanha, no período de 28 de maio a 1 de junho de 2018.

2 Universidade de Brasília (UNB), Brasília - DF - Brasil. Professora Associada no Departamento de Planejamento e Administração. Doutorado em Sociologia (USP). ORCID: https://orcid.org/0000-0001-70538584. E-mail: zrocha@unb.br

${ }^{3}$ Universidade de Brasília (UNB), Brasília - DF - Brasil. Licenciatura no curso de Pedagogia. ORCID: https://orcid.org/0000-0003-4506-2638 E-mail: shaymoraes@gmail.com
}

RPGE- Revista on line de Política e Gestão Educacional, Araraquara, v. 25, n. 3, p. 2794-2813, set./dez. 2021. e-ISSN: 1519-9029 DOI: https://doi.org/10.22633/rpge.v25i3.15082 
ABSTRACT: The political-pedagogical project is a school management document, mandatory for public schools, established in Brazilian federal legislation. The objective of the research was to unveil the ideology and utopia underlying the political-pedagogical projects. The empirical research of mixed methodology was carried out in two periods: 2010-2012 and 2018-2019, and employed, as a quantitative method, the inductive method, and in the qualitative basis, the Hermeneutic of Depth. The inductive method provided the cohort criteria in the data collection and the Hermeneutic of Depth provided the unveiling of the ideology and utopia hidden in the contents of the political-pedagogical projects. The qualitative analysis, through the Hermeneutic of Depth, resorted to the concepts of ideology and utopia in the Mannheimian perspective. The analysis was able to identify four ideological components and one utopian component.

KEYWORDS: School management. Democratic management. Strategic planning. Depth hermeneutics. Mannheimian theory.

\section{Introito}

Este artigo descreve e analisa os resultados de pesquisa empírica realizada no Distrito Federal, no período inicial de 2010-2012, com continuação em 2018-2019.

O objetivo geral da pesquisa foi identificar a ideologia e a utopia subjacentes em projetos políticos-pedagógicos de escolas públicas. O problema de pesquisa que norteou a investigação foi o de saber como e se a ideologia e a utopia estão subsumidas nas práticas escolares, de tal forma que se consubstanciam no conteúdo do planejamento estratégico das escolas.

O artigo subdivide-se em cinco partes: (i) gestão democrática, planejamento estratégico e projeto político pedagógico; (ii) percursos metodológicos; (iii) ideologia e utopia; (iv) Hermenêutica de Profundidade: ideologia e utopia subjacentes; e (v) considerações finais.

\section{Gestão democrática, planejamento estratégico e Projeto Político-Pedagógico (PPP)}

O modelo de gestão adotado na rede pública de educação básica brasileira é a gestão democrática, estabelecido na Constituição da República Federativa do Brasil, de 1988 (CF 88) e na Lei de Diretrizes e Bases da Educação Nacional, de 1966 (LDB 96). O Distrito Federal referendou a gestão democrática como modelo em seu subsistema público de ensino por intermédio de lei distrital de 2012.

A literatura acadêmico-científica do setor educacional, que tem por objeto de estudo a gestão escolar, é unânime em considerar a necessidade e a importância do projeto político- 
pedagógico como instrumento da gestão democrática, pois este define a missão da unidade escolar; esclarece os princípios norteadores que fundamentam as práticas escolares; estabelece os objetivos que a escola almeja alcançar; determina metas e estratégias a serem atingidas; organiza os critérios da avaliação institucional. Com isso, o PPP auxilia a escola a delinear sua identidade e a construir a autonomia pedagógica e de gestão da escola.

Como instrumento de gestão democrática, trata-se de planejamento estratégico porque consiste em um "[...] esforço disciplinado e consistente, destinado a produzir decisões fundamentais e ações que guiam a organização escolar, em seu modo de ser e de fazer, orientado para resultados, com forte visão de futuro" (LÜCK, 2000, p. 10). No processo de elaboração do PPP, toda a organização escolar é repensada e analisada: a estrutura física; os recursos materiais e humanos; as atividades a serem desenvolvidas. A organização escolar é repensada e analisada em função da proposta curricular; em relação ao contexto políticosocial local no qual a escola está inserida; em relação às estruturas de poder regionais e nacionais às quais a escola está submetida; em direção dos objetivos pedagógicos a serem atingidos pela comunidade.

O projeto político-pedagógico (PPP) é um instrumento da gestão estratégica de cada escola pública de educação básica no Brasil e, como tal, trata-se de documento obrigatório a partir da promulgação da lei federal nº 9.394, de 20 de dezembro de 1996, a Lei de Diretrizes e Bases da Educação Nacional, que estabelece no inciso I do art. 12 que compete aos estabelecimentos de ensino "elaborar e executar sua proposta pedagógica". O PPP constitui planejamento estratégico porque os elementos constitutivos desse modelo de planejamento encontram-se presentes no documento: organização da rotina do trabalho; existência de objetivos; existência de metas, estratégias e prazos de execução; visão de futuro; definição de mecanismos de avaliação do trabalho. O PPP, como planejamento estratégico, na fase da avaliação, organiza e coleta dados objetivos para o contínuo trabalho de reelaboração do planejamento, da organização escolar e mesmo da comunidade local, no entorno da unidade escolar.

O PPP está também estabelecido na lei distrital no 4.751, de 07 de fevereiro de 2012, que dispõe sobre o sistema de ensino e a gestão democrática do subsistema de ensino público do Distrito Federal, que obriga as escolas públicas de educação básica do Distrito Federal a “[...] formular e implementar seu projeto político-pedagógico, em consonância com as políticas educacionais vigentes e as normas e diretrizes da rede pública de ensino do Distrito Federal" (DISTRITO FEDERAL, 2012, art. 4º caput). Assim, o PPP é um instrumento de orientação para as ações das unidades escolares pelo período de quatro anos (DISTRITO 
FEDERAL, 2012, art. 17). Cada grupo gestor, ao assumir a direção do estabelecimento, deve elaborar o seu plano de ação para o período de gestão.

Fator importante na gestão democrática é a participação da comunidade nas decisões da unidade escolar. A elaboração do PPP, portanto, é definida como coletiva pela legislação: "cabe à unidade escolar, considerada a sua identidade e de sua comunidade escolar, articular o projeto político-pedagógico" (DISTRITO FEDERAL, 2012, art. 4º Parágrafo único). O Projeto Político-Pedagógico é elemento estrutural do modelo de gestão democrática, pois o PPP provoca reflexões sobre o cotidiano escolar e, ao mesmo tempo, constitui um reflexo deste. Esta reflexão é ação que necessita tempo e continuidade para se consolidar. Para que esta reflexão seja profunda e espelhe com fidedignidade a realidade da unidade escolar, seus objetivos e valores, é mister a participação de todos os segmentos da comunidade escolar na elaboração do PPP: docentes, discentes, funcionários, técnico-administrativos e de apoio e equipe gestora.

Por ser instrumento do modelo de gestão democrática, o PPP não pode e não deve ser elaborado apenas pela equipe gestora da unidade escolar. A participação coletiva é importante para consolidar a autonomia e a identidade da comunidade escolar (VEIGA, 2011). Por todo o exposto, o PPP é o planejamento estratégico da escola ao mesmo tempo de caráter político e pedagógico.

O PPP é um documento político porque sua ação é intencional, de sentido explícito, e com um compromisso definido coletivamente. Está articulado aos interesses e necessidades sociopolíticos da comunidade escolar, assim como com o compromisso de formação das gerações futuras, para a sociedade da qual a escola é parte integrante. O PPP é um planejamento estratégico sociopolítico das atividades pedagógicas que contribuem para o desenvolvimento das funções sociais, pedagógicas e políticas da escola e, por ser um planejamento estratégico que abarca a totalidades das atividades escolares, requer participação consciente e intencional de cada segmento da comunidade escolar, em relação à missão e aos objetivos que a unidade escolar almeja atingir.

O PPP é também um documento pedagógico porque subsume, em seu conteúdo, os elementos constitutivos do trabalho pedagógico escolar. Os elementos constitutivos e integrantes do trabalho pedagógico escolar são seis: as finalidades da escola; a estrutura organizacional; o currículo (os conteúdos); o tempo; os processos decisórios internos; e a avaliação. Como planejamento estratégico, o PPP questiona, analisa, organiza, delineia e explicita todos os elementos partícipes do trabalho pedagógico escolar. 
As finalidades que a escola pode desempenhar junto à comunidade que a compõe e entorna sua territorialidade estão relacionadas aos objetivos sociopolíticos que a escola se atribui e também às finalidades sociais, culturais e educacionais que a sociedade e a comunidade lhe atribuem. O processo de elaboração coletiva do PPP deve ponderar sobre esses aspectos, os deliberando e os definindo nesse planejamento estratégico.

A estrutura organizacional, segundo elemento constitutivo, é composta por dois tipos de estrutura: administrativa e pedagógica. A estrutura administrativa assegura a organização, a alocação e a gestão de recursos humanos, prediais, materiais e financeiros. A estrutura pedagógica organiza as funções educativas, interrelacionando pessoas, conhecimento, tempo e atividades.

Os conteúdos disciplinares são o terceiro elemento constitutivo do trabalho pedagógico escolar e precisam ser considerados não como conhecimento neutro, mas como espaço de poder, de controle social, de transmissão ideológica, de interrelações entre fronteiras culturais, de formação de identidades e de diferenças (MACEDO, 2006). O PPP, como planejamento estratégico do trabalho escolar, questiona, reflete e também minudencia as formas como o currículo será operacionalizado, enriquecido e adaptado, por e para àquela comunidade.

O quarto elemento constitutivo do trabalho pedagógico escolar, o tempo, está diretamente relacionado à qualidade do trabalho pedagógico e ao bem-estar dos atores do processo educacional. O planejamento estratégico deve prever períodos de tempo de trabalho individual; de reflexão coletiva; de atividades lúdicas; de intervalos ociosos; e para cada etapa das atividades pedagógicas. A organização do tempo no processo educacional permite, ao mesmo tempo, o controle: dos conteúdos disciplinares, considerando os aspectos de profundidade e de abrangência; do espaço escolar; das relações intersubjetivas; das atividades desenvolvidas, em termos de continuidade e/ou de ruptura.

O penúltimo elemento constitutivo do trabalho pedagógico escolar, os processos decisórios internos, amalgama todos os outros na funcionalidade da unidade escolar. Como se darão as deliberações da comunidade? Quais segmentos terão direito à participação e com qual peso e percentual? Quais tipos de decisões cada segmento terá direito ao voto deliberativo? O planejamento estratégico, que é o PPP, deve minudenciar todos esses aspectos.

Por fim, a avaliação, tanto pedagógica quanto institucional, engloba a criação de mecanismos de acompanhamento, de critérios objetivos nos quais se deve basear qualquer tipo de avaliação, inclusive do próprio PPP. Por conseguir correlacionar todas essas nuanças 
do processo educacional, o projeto político-pedagógico é também um instrumento pedagógico da gestão escolar.

\section{Percursos metodológicos}

A pesquisa adotou a metodologia mista na análise do objeto de estudo e processou-se em duas fases: de 2010 a 2012, e de 2018 a 2019. A primeira fase da pesquisa (2010-2012) possibilitou conhecer o universo e distinguir as categorias presentes nos Projetos Políticos Pedagógicos. A segunda fase da pesquisa (2018-2019) permitiu um mergulho mais profundo na cultura e na identidade de cada escola pesquisada. A comparação das duas fases possibilitou comprovar simetrias e assimetrias de valores e mentalidades de cada comunidade escolar investigada. Este procedimento metodológico propiciou uma visão geral da ideologia e utopia presentes na rede escolar pública do Distrito Federal. Os métodos empregados, nas duas fases, foram o indutivo e a Hermenêutica de Profundidade (HP).

A metodologia mista empregou, como método quantitativo, o indutivo, que possibilitou a generalização dos resultados para o universo pesquisado, a partir da amostragem utilizada para a coleta dos documentos. A amostra usada foi a aleatória por conglomerados. Escolheu-se as regiões administrativas do Distrito Federal com maior contingente populacional e, nessas, coletou-se os PPP's nas escolas públicas urbanas com maior quantidade de matrículas no ensino médio propedêutico.

O DF tinha, em 2012, o universo de 557 escolas públicas urbanas. Entretanto, esta rede contempla 17 categorias de escolas que ministram diferentes níveis, etapas e modalidades de ensino. As categorias que ministram ensino médio propedêutico regular eram e ainda são: Centro Educacional e Centro de Ensino Médio. Assim, o universo pesquisado era de 78 escolas (CODEPLAN, 2013) e a amostra deste subuniverso foi dez unidades escolares, concentrando-se naquelas que apresentavam maior número de matrículas nesta etapa da Educação Básica.

No período de 2018 a 2019 o DF apresenta o total de 603 escolas públicas urbanas, donde se constata que houve crescimento de $8,2 \%$ no quantitativo dessa categoria de escolas, segundo o Censo Escolar de 2019 (DISTRITO FEDERAL, 2019). Dentre essas, 88 são de ensino médio propedêutico. Nessa segunda etapa, a amostra manteve-se nas mesmas dez unidades pesquisadas no período anterior, a fim de analisar mudanças e/ou continuidades de conteúdo nos documentos institucionais. 
No total, foram coletados vinte PPP's, mas a computação dos dados deu-se por unidades escolares, uma vez que os dados foram coletados nas mesmas escolas nos dois períodos. Contabilizar os dados em duplicidade inflaria os valores, o que falsearia a realidade. A utilização das mesmas técnicas nos dois períodos diferentes de tempo possibilitou detectar continuidades e/ou descontinuidades de valores, de identidade, de mentalidades dos atores institucionais que atuam na rede pública de ensino médio propedêutico do DF.

A abordagem qualitativa deu-se por intermédio da Hermenêutica de Profundidade (THOMPSON, 2009), que propiciou desvelar os componentes ideológicos e utópicos ocultos nos conteúdos objetivos. O estudo da ideologia e utopia presentes e atuantes em determinado contexto histórico e manifestos em determinadas formas simbólicas somente tem sentido se se busca atingir a matriz de pensamento de determinada sociedade ou de determinados grupos sociais, ainda que estes tenham reverberações individuais.

A matriz de pensamento da Hermenêutica de Profundidade (HP) é o mannheimiano, a partir da concepção total de ideologia. Mannheim (1976) explica que a ideologia é um fenômeno total que constitui o substrato o qual amalgama as interações societais ao mesmo tempo que cria uma nuvem a ensombrecer o pensamento humano e a sua compreensão da realidade:

As ideologias são as idéias (sic) situacionalmente transcendentes que jamais conseguem de facto a realização de seus conteúdos pretendidos. Embora se tornem com frequência motivos bem intencionados (sic) para a conduta subjetiva do indivíduo, seus significados, quando incorporados efetivamente à prática, são na maior parte dos casos, deformados (MANNHEIM, 1976, p. 218).

Devido a essa especificidade da ideologia, Mannheim fincou as bases epistemológicas para estudá-la. Como fenômeno total, a ideologia deve ser pesquisada, primeiramente, a partir de suas raízes sociais e sem qualquer conotação valorativa do fenômeno em si. A aplicação desses dois princípios epistemológicos permite chegar à estrutura da mentalidade de determinada sociedade e/ou grupo social, em determinado tempo histórico. Restringir-se às manifestações individuais da ideologia seria manter-se na superficialidade e na incompletude do fenômeno, sem chegar ao substrato que explica os valores e comportamentos sociais, grupais e individuais.

A partir deste solo, Thompson (2009) delimitou os procedimentos metodológicos para estudar as manifestações simbólicas da ideologia e da utopia no pensamento contemporâneo: a Hermenêutica de Profundidade. O método está, portanto, fincado em território mannheimiano. 
A HP estrutura-se em três fases: análise sócio-histórica, análise formal ou discursiva, e a interpretação/reinterpretação. A análise sócio-histórica da ideologia e da utopia considera que as manifestações simbólicas, eivadas de ideologia e/ou de componentes utópicos, são constructos abstratos criados para responder a necessidades e interesses das ambiências socioculturais ou dos grupos que lhes estruturaram. A análise sócio-histórica da ideologia e da utopia deve observar a produção, a circulação e a recepção das formas simbólicas em estudo, considerando tanto os aspectos institucionais, quanto os grupais e individuais, além de atentar-se para as relações de dominação que as formas simbólicas consolidam ou rompem. A pesquisa contemplou essa fase ao mostrar a relação entre o conteúdo dos PPP's e as fontes teórico-científicas das quais tiraram os conceitos e os princípios.

A segunda fase da Hermenêutica de Profundidade - a análise formal ou discursiva prende-se à forma de manifestação do fenômeno: linguagem; padrões; regras. Esta fase foi contemplada na pesquisa por meio da análise de conteúdo e categorização, o que permitiu destrinchar o conteúdo dos PPP's em oito categorias de análise diferentes ${ }^{4}$.

A última fase da HP é a interpretação da doxa ideológica e/ou utópica, explicando o significado dos conteúdos objetivos a partir de suas relações com a estrutura social e com os objetivos dos grupos, ou seja, com a ambiência social que produziu àquele tipo de pensamento. Isso foi o que foi realizado na pesquisa, pois analisar o conteúdo dos Projetos Político-Pedagógicos permitiu desvelar os componentes ideológicos e utópicos subjacentes ao conteúdo.

Entretanto, calcado no princípio epistemológico de que o sujeito cognoscente é, também, um sujeito imerso em determinada ambiência social e, portanto, sofre influências destas, Thompson (2009) alerta que intentar uma interpretação é sempre projetar um significado dentre os vários possíveis, pois a reinterpretação da doxa ideológica e utópica depende das interações do sistema de pensamento com os demais aspectos da realidade: é uma questão de perspectiva. Assim, é mister explicar que a interpretação que esta pesquisa empreendeu consiste em uma perspectiva correlacionada à ambiência social na qual estão inseridos, tanto os atores criadores do fenômeno estudado, quanto os sujeitos cognoscentes, produtores do conhecimento. Coloca-se, assim, em prática, o princípio metodológico thompsoniano, cuja fonte, na verdade, é Mannheim (2001). O rigor metodológico empregado objetivou alcançar um relativo distanciamento e, portanto, aproximar-se da validade científica, pois, como ensinou Weber (1992), a matriz desta linhagem de pensamento, a

${ }^{4}$ Esta parte da pesquisa foi objeto de outro artigo, submetido a outro periódico pois, por ser muito extensa, não cabia nas dimensões deste artigo. 
neutralidade científica nunca será alcançada, mas terá sempre que ser perseguida por intermédio do rigor metodológico.

\section{Ideologia e utopia: aspectos conceituais}

O conceito de ideologia utilizado neste trabalho é o cunhado por Mannheim (1976), o qual adota a concepção epifenomênica marxista, considerando-a um fenômeno total que somente pode ser compreendido em íntima conexão com o contexto social que a produziu. Para este, na palavra ideologia está implícita "a noção de que, em certas situações, o inconsciente coletivo de certos grupos obscurece a condição real da sociedade, tanto para si como para os demais, estabilizando-a" (MANNHEIM, 1976, p. 66).

Para Mannheim (1976), o conceito de ideologia não carrega em si conotação negativa, pois o significado do mundo que compõe uma estrutura historicamente determinada somente pode ser alcançado por meio de uma análise não-valorativa da ideologia que constitui o universo cultural de determinada realidade social. Com esta posição epistemológica, consegue-se captar o fluxo das realidades em constantes mudanças.

Já utopia é o pensamento que constitui uma variação do presente, na busca de um futuro ideal. A utopia aspira por um ideal ou por um estado atual melhorado. Não se pode reduzi-la a um impulso psicológico, sonho, fantasia, desejo ou vontade. A utopia não significa a busca da vida perfeita, mas um projeto que pode ser alcançado a depender da ação coletiva. O pensamento utópico consiste em uma crítica social com projeção de saída do estado atual das coisas na direção de um futuro almejado (MANNHEIM, 1976).

Um pensamento é considerado utópico quando está fundado na experiência e na prática, mas orienta-se para objetos que não existem na realidade, no tempo atual, ao contrário, estão sempre projetados para o futuro. As utopias são orientações que vão além da realidade e que tendem a transformar comportamentos que estremecem a ordem das coisas naquele determinado tempo e espaço histórico. Quando uma orientação propõe acabar com a ordem existente, ela se torna utópica (MANNHEIM, 1976).

Há necessidade de se compreender e distinguir as orientações utópicas das ideológicas, pois estas têm funções diferentes no meio social. As ideologias, por mais que possam transcender em relação à ordem existente, não oferecem possibilidades revolucionárias; por outro lado, elas justificam o status quo, uma vez que buscam manter o pensamento social atual. Mesmo assim uma ideologia pode tornar-se utópica, quando esta é incorporada a 
imagens que exprimem uma vontade e conduzem a uma mudança de comportamento (MANNHEIM, 1976).

A ordem operante baseia-se em uma estrutura política e econômica e contém concepções que podem ser consideradas transcendentes ou irreais. As ideologias são ideias transcendentes que jamais conseguem realizar os conteúdos pretendidos. O indivíduo sente-se forçado e preso a uma conduta particular, podendo estar dentre uma série de mentalidades ideológicas, que são: mentalidade bem intencionada transcendente; mentalidade hipócrita e mentalidade ideológica. A mentalidade bem intencionada transcendente é o pensamento socialmente determinado na ambiência social e no tempo histórico que produziu este tipo de mentalidade. Neste tipo de mentalidade, o ator social está impedido de tomar consciências das incongruências da realidade porque os valores, as crenças, as representações, as pressões sociais caem sobre ele com todo o peso de ser a verdade estabelecida e ideal. A mentalidade hipócrita tem consciência das assimetrias, contradições e paradoxos da mentalidade vigentes, mas não faz a crítica, o questionamento e a propositura de alternativas porque está preso a algum interesse emocional ou político ou econômico ou ético ou moral ou filosófico ou ideológico. A mentalidade ideológica constitui uma fraude consciente, pois oculta das as assimetrias, contradições, paradoxos e desigualdades sociais, ao mesmo tempo que cria coesão entre os indivíduos ao fornecer uma base axiológica para fundamentar, justificar e explicar, tanto a realidade, quanto suas próprias ações (MANNHEIM, 1976).

As utopias também transcendem a situação atual, mas se diferenciam quando conseguem transformar a realidade histórica. Mannheim (1976) afirma que diferenciar se um pensamento é ideológico ou utópico, é extremamente difícil, pois é um conceito que envolve valores e padrões. Para fazer esta diferenciação o pesquisador deve partilhar dos sentimentos e motivações dos grupos em luta, na realidade histórica.

\section{Hermenêutica de Profundidade: ideologia e utopia subjacentes}

A Hermenêutica de Profundidade (HP), criada por Thompson (2009) a partir da hermenêutica clássica e da concepção mannheimiana de ideologia e utopia, realiza a reconstrução do significado da forma simbólica em estudo a partir da contextualização da mesma no cenário social na qual está inserida. O objetivo final da HP é compreender ${ }^{5}$ como

\footnotetext{
5 A matriz primeira da metodologia thompsoniana e da teoria mannheimiana é a lógica do pensamento weberiano na qual as Ciências da Cultura devem buscar a compreensão da ação social e seus significados (WEBER, 1992).
} 
as formas simbólicas são utilizadas em interações político-sociais que se configuram na esfera pública.

Neste estudo, a HP foi adaptada, e contemplará a interpretação que os atores escolares elaboram da doxa ideológica e utópica vigente na sociedade. Interpretação corporificada nos projetos políticos pedagógicos das escolas públicas de ensino médio do Distrito Federal, no Brasil, nos períodos de 2012 a 2014 e de 2017 a 2019 :

Negligenciar esses contextos da vida quotidiana, e as maneiras como as pessoas situadas dentro delas interpretam e compreendem as formas simbólicas que eles produzem e recebem, é desprezar uma condição hermenêutica fundamental da pesquisa [...] (THOMPSON, 2009, p. 364)

A terceira fase da HP - a interpretação/reinterpretação -, utilizada nesta pesquisa, busca desvendar as interrelações existentes entre o significado do conteúdo reproduzido na forma simbólica em estudo e as concepções de mundo hegemônicas da sociedade que as criou. É mister enfatizar que se trata sempre de um esforço de ressíntese criativa, intentando uma explicação do significado da doxa vigente inscrita na forma simbólica.

Verificou-se que os PPP's analisados incorporam princípios e valores presentes nos instrumentos normativos e nas teorias científicas, incidindo muito pouco em componentes ideológicos. Foram detectados os seguintes princípios norteadores que não podem ser considerados, de todo, componentes ideológicos porque são oriundos de análises acadêmicocientíficas: a) educação como força de mudança social; b) escola como instituição capaz de diminuir desigualdades sociais; c) participação comunitária como meio de resolução de conflitos e; d) ciência como guia de ações humanas. O principal componente utópico encontrado nos projetos políticos-pedagógicos analisados é a democracia como valor.

Quadro 1 - PPP que apresentam componentes ideológicos e utópico

\begin{tabular}{|c|c|c|c|c|c|}
\hline \multirow[b]{2}{*}{ ESCOLAS } & \multicolumn{4}{|c|}{ COMPONENTES IDEOLÓGICOS } & \multirow{2}{*}{\begin{tabular}{|l} 
COMPONENTE \\
UTÓPICO \\
$\begin{array}{l}\text { Democracia } \\
\text { como valor }\end{array}$ \\
\end{tabular}} \\
\hline & $\begin{array}{l}\text { Educação como } \\
\text { força de mudança } \\
\text { social }\end{array}$ & $\begin{array}{lr}\text { Escola } & \text { como } \\
\text { instituição capaz } \\
\text { de diminuir } \\
\text { desigualdades } \\
\text { sociais }\end{array}$ & $\begin{array}{l}\text { Participação } \\
\text { comunitária } \\
\text { como meio de } \\
\text { resolução de } \\
\text { conflitos }\end{array}$ & $\begin{array}{l}\text { Ciência como } \\
\text { guia de ações } \\
\text { humanas }\end{array}$ & \\
\hline Alfa & 1 & 1 & 1 & 1 & 1 \\
\hline Beta & 1 & 1 & 1 & 1 & -- \\
\hline Gama & 1 & 1 & 1 & --- & 1 \\
\hline Delta & 1 & --- & 1 & 1 & 1 \\
\hline Epsílon & --- & --- & --- & 1 & 1 \\
\hline Dzeta & --- & --- & 1 & --- & 1 \\
\hline
\end{tabular}




\begin{tabular}{|l|l|l|l|l|c|} 
Eta & 1 & 1 & 1 & 1 & 1 \\
\hline Teta & 1 & 1 & 1 & --- & 1 \\
\hline Iota & 1 & 1 & 1 & --- & -- \\
\hline Capa & 1 & 1 & 1 & 1 & 1 \\
\hline TOTAL & $\mathbf{8}$ & $\mathbf{7}$ & $\mathbf{9}$ & $\mathbf{6}$ & $\mathbf{8}$ \\
\hline
\end{tabular}

Fonte: Dados da pesquisa

Esses elementos não podem ser considerados, totalmente, componentes ideológicos, mas, ao mesmo tempo, o são. Trata-se de fenômeno dialético: ao mesmo tempo que são, também não são. Não podem ser considerados princípios ideológicos porque são oriundos de análises acadêmico-científicas e de legislação. Mas ao mesmo tempo são porque nem a legislação, nem o conhecimento acadêmico-científico são fortalezas inexpugnáveis à influência ideológica. Também porque se constata que, pelo menos dois deles $(a, b)$ desempenham duas funções sociais: criam explicação para as assimetrias, desigualdades, paradoxos e contradições sociais; e constituem-se em crenças em torno das quais se aglutinam o fazer pedagógico dos atores escolares.

A educação como força que propulsiona a mudança social no sentido da diminuição das desigualdades sociais é tema recorrente nas ciências sociais e na Ciência da Educação. Em ambas as subáreas de conhecimento, a compreensão de que a educação formal é mola propulsora da mudança social foi desenvolvida considerando-se os aspectos econômicos, sociais, políticos, culturais. O tema da educação como força capaz de diminuir as desigualdades sociais remonta aos estudos clássicos de diversos matizes teóricos, desde as primeiras décadas do século XX. O processo de generalização do conhecimento científico o transforma em senso comum e, até mesmo em componente ideológico, quando os dados da realidade contradizem a crença que o conhecimento instituiu como ideologia ${ }^{6}$.

Este componente ideológico é encontrado em 70\% dos PPP's, que consideram essa possibilidade como resultado das interações sociais, enfatizando mais os aspectos culturais do que o conhecimento como insumo para formação do mercado de trabalho. O conteúdo dos PPP's analisados oculta a mensagem ideológica que a escola é um espaço relacional capaz de contribuir para a mudança social e, portanto, para a redução das desigualdades sociais, mas formando o cidadão consciente para um contexto democrático e não, necessariamente, por democratizar o conhecimento científico:

${ }^{6}$ Mannheim (1976) explica que uma das funções da ideologia é justificar as lacunas existentes entre as crenças e a realidade, não adotando a conotação negativa e valorativa de ideologia. 
[...] a construção de uma escola pública que eduque de fato para o exercício pleno da cidadania e seja instrumento real de transformação social, espaço em que se aprenda a aprender, a conviver e a ser com e para os outros, contrapondo-se ao atual modelo gerador de desigualdades e exclusão social que impera das políticas educacionais de inspiração neoliberal (SEEDF, 2010b, p. 39).

Constata-se que esses documentos institucionais ignoram ou desconhecem a realidade da juventude brasileira contemporânea, na qual 70\% da população jovem não está inserida nem em relações de trabalho formal, nem em espaços de educação formal. Trata-se de uma inatividade que atinge a maioria da juventude de 16 a 24 anos, com concentração nas mulheres, pobres, pretas e mães (MDSCF, 2013). A pesquisa denominou esta geração como "nem, nem", que significa 'nem estuda, nem trabalha' ou 'neither in employment nor in education or trainning' (NEET). Esse dado estarrecedor comprova que a escolaridade e o trabalho não são valores para a geração contemporânea de jovens brasileiros. A crença na educação como mola propulsora de ascensão social ficou nas gerações mais velhas.

Nos PPP's analisados, encontramos, na categoria missão, que a função das escolas é formar cidadãos críticos e atuantes para a vida, para a sociedade democrática e para o mercado de trabalho: "Formar cidadãos participativos, através da ação educacional, de práticas e princípios éticos aliados ao respeito à dignidade humana [...]” (SEEDF, 2019, p. 60). A Educação é concebida nessas missões, como força catalizadora para a mudança individual e, consequentemente, para a mudança social, ao fornecer aos indivíduos os instrumentais cognitivos e de conhecimentos para se inserirem na vida produtiva, política e cultural de forma ativa, agindo como atores na direção da mudança social. A escola é, nessa concepção, a instituição responsável por democratizar esses insumos. Mannheim (1972) caminha no rastro deste pensamento ao conceber a educação como uma 'técnica social' imprescindível na constituição de uma sociedade democrática e planejada.

No Brasil, a escolarização ainda é vista como fator de redução das desigualdades sociais e, portanto, de mudança social. Entretanto, essa crença embute a falsa noção que as “[...] desigualdades de renda são diretamente ligadas às diferenças de qualificação" (SOBRAL, 1980, p. 41). Estudos provam que há fatores estruturais que mantêm e reproduzem as desigualdades sociais e que a educação, por si só, não constitui força suficiente para transformar a sociedade brasileira em uma sociedade com menos desigualdade social e com mais justiça social: 
a expectativa de vida dos habitantes, fatores étnicos, estrutura etária da população, qualidade da infraestrutura existente, presença/ausência de estímulos ao desenvolvimento e fatores históricos (SALVATO; FERREIRA; DUARTE, 2010, p. 783).

Em realidade, a correlação de fatores é inversa do que está inscrito nos projetos político-pedagógicos. Em média, as condições econômicas de renda são condicionantes para o acesso à escolaridade, em especial à mais elevada: “o nível de escolarização atingido pelos jovens seja predito pelos fatores indicativos da situação socioeconômica, do capital cultural e do capital social acessível a suas famílias" (SILVA; HASENBALG, 2000, p. 10).

O que se constata é que a crença impressa em 80\% dos PPP's analisados contrasta com a realidade brasileira, tanto que, a fim de diminuir a brutal desigualdade de educação, cinco governos e meio ${ }^{7}$ implementaram políticas públicas educacionais para diminuir as desigualdades educacionais no Brasil e tiveram êxito, mas as estruturas socioeconômicas, tanto como político-culturais que mantêm a desigualdade econômica não foram tocadas. Os estudos científicos, de várias décadas diferentes, corroboram que o poder da educação para diminuição das desigualdades é limitado: "as simulações indicam também que, mesmo no longo prazo, há limites claros para os impactos que a educação pode ter sobre a distribuição de renda" (MEDEIROS; BARBOSA; CARVALHAES, 2019, p. 45).

O modelo de gestão democrática, tanto da sociedade, quanto da escola, é encontrado em 50\% dos PPP's. Neste, enfatiza-se o papel da participação dos indivíduos e dos grupos. A participação nos processos decisórios escolares, comunitários e societais é considerada ato de liberdade, momento de igualdade, e espaço relacional de poder. Por outro lado, nos documentos institucionais analisados, $90 \%$ consideram a participação como meio de resolução de conflitos. Esta crença anda de mãos dadas com a missão da escola de formar cidadãos críticos e atuantes que "passem a protagonizar o desenvolvimento da cidade, nas lutas por melhores condições para suas quadras, seu bairro, sua rua” (SEEDF, 2010b, p. 08).

A crença pode ser considerada componente ideológico porque desconsidera as injunções objetivas que a economia, a política, a cultura impõem aos indivíduos e aos grupos.

\footnotetext{
${ }^{7}$ Os governos foram: Fernando Henrique Cardoso (1995-1999 e 1999-2003); Luís Inácio - Lula - da Silva (2003-2007 e 2007-2011; e Dilma Vana Roussef (2011-2014 e 2014-2016). As políticas educacionais foram: Fundo Nacional de Desenvolvimento do Ensino Fundamental e de Valorização do Magistério - FUNDEF (19962008); Programa Nacional de Renda Mínima vinculada à educação - Bolsa Escola (2001-2004); Fundo Nacional de Desenvolvimento da Educação Básica e de Valorização dos Profissionais da Educação - FUNDEB (20092020); Programa Bolsa Família (2004-*); Programa Universidade para Todos - Prouni (2005-*); Programa de Apoio a Planos de Reestruturação e Expansão das Universidades Federais - Reuni (2007-2012). * Os governos pós 2016 mantiveram essas políticas públicas de educação porque algumas foram consubstanciadas como políticas de Estado, aprovadas pelo Legislativo federal, transformadas em emendas constitucionais e em leis federais.
} 
O distanciamento entre a crença e a realidade objetiva é uma das idiossincrasias da ideologia, alocando o poder de mudança social nos indivíduos que participam, ou seja, recai no individualismo.

A partir da Revolução Industrial e da Revolução Francesa, a escola, no mundo ocidental, consolida-se como espaço de difusão do conhecimento científico, ainda que promovendo sua simplificação, adaptando-o ao nível de escolaridade e à faixa etária do público alvo. Esta compreensão corrente de uma das funções sociais da escola está atrelada à concepção de ciência como guia das ações humanas, vigente no mundo ocidental moderno e contemporâneo.

A ciência e a tecnologia passaram, cada vez mais, a serem valorizadas em diversos grupos sociais, sendo concebida como possibilidade de explicação da realidade e de resolução de problemas sociais. A crença no poder da ciência moderna e do conhecimento científico perpassa diversas sociedades na contemporaneidade, num crescendo, após a segunda guerra mundial e após a terceira revolução tecnológica da década de setenta do século XX (SHWARTZMAN, 2008).

Esta concepção ideológica foi encontrada em $60 \%$ dos projetos político-pedagógicos analisados. Afirmam que a educação voltada para a formação de cidadãos atuantes deve proporcionar conhecimentos científicos a fim de que os questionamentos sobre o mundo possam ser mais bem respondidos e os problemas solucionados. Tal concepção da função social do conhecimento científico e da escola como difusora deste é explícita em vários PPP's: “evidenciar através do domínio dos fundamentos científicos-tecnológicos, a importância da pesquisa e do avanço das ciências, no sentido de responder aos desafios e questionamento do mundo moderno" (SEEDF, 2010a, p. 08).

A democracia é apresentada, nos PPP's analisados, como componente primordial para se alcançar uma sociedade mais justa e igualitária, para a mudança não só a gestão da escola, como também da educação, da política, mas, principalmente, da sociedade. A democracia é afirmada como ideal a ser plasmado nas diferentes instituições sociais:

Garantir o diálogo e a relação de troca com a comunidade escolar para uma educação libertadora e inclusiva com fins à transformação política das realidades de desigualdade social, em suas transversalidades, e à garantia dos processos democráticos na escola e na sociedade (SEEDF, 2018, p. 20).

O componente utópico da democracia como valor é encontrado em $80 \%$ dos PPP's analisados, nos quais se encontra a concepção que a democracia é fator primordial para a formação de cidadãos críticos e atuantes; para a consolidação de uma escola pública de 
qualidade; e para "[...] desenvolver as capacidades e as habilidades voltadas para uma participação responsável e solidária na sociedade, através de uma prática democrática, visando o pleno exercício da cidadania" (SEEDF, 2010a, p. 08).

A democracia, no caso brasileiro, constitui um norte para onde os movimentos sociais, as políticas, as práticas escolares almejam chegar. A sociedade e o Estado brasileiro, assim com a educação formal, não podem ser, de todo, consideradas efetivamente democráticas, posto que há atores sociais excluídos desses processos, sem participação real, sem direitos de cidadania. Então, no caso brasileiro, a democracia ainda é um projeto de futuro a ser plasmado nas práticas sociais e escolares.

Encontrar a democracia como componente utópico a ser incorporado cotidianamente nas práticas escolares, para ser plasmado nas instituições sociais não é surpresa, uma vez que os PPP's se fundamentam em teorias científicas e em documentos legais que adotam o modelo de gestão democrática na escola, a democracia como valor para o social, e a interrelação entre ambos: “[...] a gestão democrática é um passo importante para o aprendizado da democracia" (SEEDF, 2018, p. 04).

\section{Considerações finais}

Para Mannheim (1976), o pensamento é determinado socialmente, de acordo com o grupo social que o produziu. O pensamento produz manifestações individuais e por subgrupos em uma sociedade, mas não se trata, em absoluto, de fenômeno individual.

A análise de conteúdo e a hermenêutica de profundidade realizadas nos conteúdos dos projetos políticos-pedagógicos de escolas públicas de ensino médio do Distrito Federal nos períodos de 2010 a 2012 e de 2018 a 2019 propiciou capturar o pensamento coletivo dos segmentos sociais que se constituem sujeitos do processo pedagógico nessa instituição. A análise dos PPP's coletados evidenciou que estes estão fundamentados em documentos legais e em teorias científicas das áreas de humanas e sociais. A fundamentação legal ancora-se na Constituição Federal de 1988, na Lei de Diretrizes e Bases da Educação Nacional (9.394/1996), nas Diretrizes Curriculares Nacionais para a Educação Básica, nos Parâmetros Curriculares Nacionais e no Currículo de Educação Básica do Distrito Federal.

Em suma, os componentes ideológicos subjacentes nos PPP's analisados ancoram-se na crença de que a educação oferecida na escola pode resolver os problemas da sociedade. Creem que a escola tem como missão, objetivos e/ou princípios formar o cidadão que atue de 
maneira crítica e que transforme o mundo atual, na direção de uma sociedade democrática, apoiada em conhecimentos racionais.

Entretanto, o que se vê na contemporaneidade é o contrário, com múltiplas manifestações de ódio pelas chamadas mídias sociais ${ }^{8}$; $\operatorname{com}_{\text {movimentos negacionistas }}{ }^{9}$ da ciência, da democracia, da pandemia provocada pelo coronavírus, de vacinas; e com grupos terraplanistas ${ }^{10}$. Os documentos institucionais relegam à secundariedade fatores essenciais para a transformação das estruturas sociais tais como a eliminação da imensa concentração de riquezas que caracteriza o Brasil desde o processo colonial; a promoção de uma distribuição de renda mais justa e menos desigual; à promoção do acesso às benesses sociais como trabalho, moradia, saúde, infraestrutura urbana e a própria escolaridade formal. Os PPP's analisados incorrem na crença ingênua que os conhecimentos fornecidos na escola são suficientes para mudar essa realidade social.

\section{REFERÊNCIAS}

BRASIL. Constituição da República Federativa do Brasil de 1988. Disponível:

http://www.planalto.gov.br/ccivil_03/constituicao/constituicaocompilado.htm. Acesso: 13 jul. 2020.

BRASIL. Lei n. 9.394, de 20 de dezembro de 1996. Estabelece as diretrizes e bases da educação nacional. Brasília, DF, 1996. Disponível:

http://www.planalto.gov.br/ccivil_03/leis/19394.htm. Acesso: 13 jul. 2020.

BRASIL. Ministério do Desenvolvimento Social e Combate à Fome. Os jovens que não estudam nem trabalham no Brasil: discussão conceitual, caracterização e evolução de 2001 a 2011. Brasília, DF: MDSCF, Estudo Técnico nº 03/2013.

CODEPLAN. Companhia de Planejamento do Distrito Federal. Educação Básica no Distrito Federal. Brasília, DF: Codeplan, 2013.

DE ALBUQUERQUE, A.; QUINAN, R. Crise epistemológica e teorias da conspiração: o discurso anti-ciência do canal "Professor Terra Plana". Revista Mídia e Cotidiano, v. 13, n. 3, p. 83-104, 2019.

DISTRITO FEDERAL. Lei n. 4.751, de 07 de fevereiro de 2012. Dispõe sobre o Sistema de Ensino e a Gestão Democrática do Sistema de Ensino Público do Distrito Federal. Disponível: http://www.sinj.df.gov.br/sinj/Norma/70523/Lei_4751.html. Acesso: 13 jul. 2020.

${ }^{8}$ Ver: Stroppa e Rothenburg (2015), Stein, Nodari e Salvagni (2018) e Sarlet (2019).

${ }^{9}$ Ver: Pivaro e Júnior (2020), Ramalho (2020), Vignoli, Rabello e Almeida (2021).

${ }^{10}$ Ver De Albuquerque e Quinan (2019) e Marineli (2020).

RPGE- Revista on line de Política e Gestão Educacional, Araraquara, v. 25, n. 3, p. 2794-2813, set./dez. 2021. e-ISSN: 1519-9029 
DISTRITO FEDERAL. Secretaria de Estado de Educação. Censo Escolar 2019: cadastro das unidades escolares do Distrito Federal. Disponível: http://www.educacao.df.gov.br/wpconteudo/uploads/2019/07/cadastro_completo_2019_15.jun_.pdf. Acesso: 13 jul.2020.

LÜCK, H. A aplicação do planejamento estratégico na escola. Gestão em Rede, n. 19, p. 813, abril, 2000.

MACEDO, E. Currículo: Política, Cultura e Poder. Currículo sem Fronteiras, v. 6, n. 2, p. 98-113, jul./dez. 2006.

MANNHEIM, K. Ideologia e Utopia. 3. ed. Rio de Janeiro, RJ: Zahar Editores, 1976.

MANNHEIM, K. Liberdade, Poder e Planificação Democrática. São Paulo, SP: Mestre Jou, 1972.

MANNHEIM, K. Sociologia da Cultura. São Paulo, SP: Perspectiva S.A., 2001.

MARINELI, F. O terraplanismo e o apelo à experiência pessoal como critério epistemológico. Caderno Brasileiro de Ensino de Física, v. 37, n. 3, p. 1173-1192, 2020.

MEDEIROS, M.; BARBOSA, R. J.; CARVALHAES, F. Educação, desigualdade e redução da pobreza no Brasil. Rio de Janeiro, RJ: Ipea, 2019.

PIVARO, G. F.; JÚNIOR, G. G. O ataque organizado à ciência como forma de manipulação: do aquecimento global ao coronavírus. Caderno Brasileiro de Ensino de Física, v. 37, n. 3 , p. 1074-1098, 2020.

RAMALHO, V. G. O Brasil do negacionismo: uma análise da disputa entre pós-verdade e ciência. O Manguezal: Revista de Filosofia, v. 1 n. 5, jan./jun. 2020.

SALVATO, M. A.; FERREIRA, P. C. G.; DUARTE, A. M. O impacto da escolaridade sobre a distribuição de renda. Estudos Econômicos, São Paulo, v. 40, n. 4, p. 753-791, out./dez. 2010 .

SARLET, I. W. Liberdade de expressão e o problema da regulação do discurso do ódio nas mídias sociais. Revista Estudos Institucionais, v. 5, n. 3, p. 1207-1233, set./dez. 2019.

SCHWARTZMAN, S. Ciência, tecnologia, tecnocracia e democracia. In: SCHWARTZMAN, S. Ciência, universidade e ideologia: a política do conhecimento. Rio de Janeiro, RJ: Centro Edelstein de Ciências Sociais, 2008. p. 07-17.

SECRETARIA DE ESTADO DA EDUCAÇÃO DO DISTRITO FEDERAL. Proposta pedagógica: Centro de Ensino Médio 01 do Gama. DF: SEEDF, 2010a.

SECRETARIA DE ESTADO DA EDUCAÇÃO DO DISTRITO FEDERAL. Proposta pedagógica: Centro de Ensino Médio 417 de Santa Maria. DF: SEEDF, 2010b.

SECRETARIA DE ESTADO DA EDUCAÇÃO DO DISTRITO FEDERAL. Projeto político-pedagógico professora Ineide Santini. Centro de Ensino Médio 01 de São Sebastião. DF, 2018. 
SECRETARIA DE ESTADO DA EDUCAÇÃO DO DISTRITO FEDERAL. Educar na diversidade: Projeto Político-Pedagógico. Centro de Ensino Médio 01 do Gama, triênio 2017-2019. DF, 2019.

SILVA, N. V.; HASENBALG, C. Tendências da desigualdade educacional no Brasil. Dados, v. 43, n. 3. Rio de Janeiro, RJ: Iuperj, 2000.

SOBRAL, F. Educação e mudança social: uma tentativa de crítica. São Paulo, SP: Cortez, 1980.

STEIN, M.; NODARI, C. H.; SALVAGNI, J. Disseminação do ódio nas mídias sociais: análise da atuação do social media. Interações, Campo Grande, v. 19, n. 1, jan./mar. 2018.

STROPPA, T.; ROTHENBURG, W. C. Liberdade de expressão e discurso de ódio: o conflito discursivo nas redes sociais. Revista Eletrônica do Curso de Direito, Santa Maria (RS), v. 10, n. 2, p. 452-468, 2015.

THOMPSON, J. B. Ideologia e cultura moderna: teoria social crítica na era dos meios de comunicação de massa. 8. ed. Petrópolis, RJ: Vozes, 2009.

VEIGA, I. P. A. Projeto político-pedagógico da escola: uma construção possível. 29. ed. São Paulo, SP: Papirus, 2011.

VIGNOLI, R. G.; RABELLO, R.; ALMEIDA, C. C. Informação, misinformação, desinformação e movimentos antivacina: materialidade de enunciados em regimes de informação. Encontros Bibli: Revista Eletrônica de Biblioteconomia e Ciência da Informação, v. 26, p. 1-31, 2021.

WEBER, M. Metodologia das ciências sociais: parte 1. São Paulo, SP: Cortez; Campinas, SP: Edunicamp, 1992.

WEBER, M. Metodologia das ciências sociais: parte 2. São Paulo, SP: Cortez; Campinas, SP: Edunicamp, 1995. 


\section{Como referenciar este artigo}

ROCHA, M. Z. B.; MORAES, S. C. Projeto político-pedagógico: ideologia e utopia. Revista on line de Política e Gestão Educacional, Araraquara, v. 25, n. 3, p. 2794-2813, set./dez. 2021. e-ISSN:1519-9029. DOI: https://doi.org/10.22633/rpge.v25i3.15082

Submetido em: 06/08/2021

Revisões requeridas em: 28/09/2021

Aprovado em: $15 / 10 / 2021$

Publicado em: 08/12/2021 